\title{
The Utility of the CPT in the Diagnosis of ADHD in Individuals with Substance Abuse: A Systematic Review
}

\section{Ortal Slobodin}

Department of Education, Ben-Gurion University, Beer-Sheva, Israel

\section{Keywords}

Attention-deficit/hyperactivity disorder - Attention . Impulsivity · Continuous performance test - Substance use disorders

\begin{abstract}
Background: Early identification of attention-deficit/hyperactivity disorder (ADHD) in individuals with substance use disorders (SUD) is important because ADHD has an adverse effect on the development and course of SUD. Given the limited validity of self-report measures of ADHD in individuals with SUD, it is important to investigate the utility of the continuous performance test (CPT) in classifying ADHD in adults with SUD. Objective: This review aims to examine the quantitative similarities and differences in CPT performance of adults with ADHD, SUD, and their comorbidity to determine if a distinct neurocognitive profile exists for each. Method: A systematic review of CPT studies that included patients with the comorbidity of ADHD and SUD and a comparison group of one of the disorders alone was conducted. The Preferred Reporting Items for Systematic Reviews and Meta-Analyses (PRISMA) guidelines were used. Results: Eight studies were identified with sample sizes ranging from $n=17$ to $n=386$. The comorbidity of ADHD and SUD was, mostly, not associated with higher rates of commission and omission errors than either disorder alone. However, the comorbidity of
\end{abstract}

ADHD and SUD was more likely to be associated with increased deficits in response time variability compared with individuals with ADHD alone. Conclusions: This review highlights the shortage of large-scale CPT research involving patients with ADHD and SUD. The CPT might be sensitive to attentional deficits, but it lacks specificity for the classification of adult ADHD, SUD, or their comorbidity, and the CPT is thus not useful in discriminating comorbid ADHD and SUD from either disorder alone. Future CPT research should explore whether specific attentional deficits account for the development and persistence of SUD. Such research should also reach beyond traditional CPT measures and include other cognitive and behavioral deficits that were associated with ADHD, such as distractibility and hyperactivity.

(c) 2020 S. Karger AG, Basel

\section{Introduction}

Attention-deficit/hyperactivity disorder (ADHD) is the most prevalent neurodevelopmental disorder of childhood, with an estimated rate of $9.4 \%$ of children in the USA [1]. The disorder is associated with adverse academic, social, emotional, and physical outcomes [2, 3] and persists into adulthood in $60 \%$ of children [4]. ADHD is strongly linked to the development of substance use disorders (SUD) [5-7], often at a very early age and with karger@karger.com

www.karger.com/ear

Karger $\stackrel{2}{*}$
(C) 2020 S. Karger AG, Basel

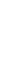

Ortal Slobodin

Deptartment of Education

Ben-Gurion University, Beer Sheva

Beer-Sheva 84105 (Israel)

ortal.slobodin@gmail.com 
a faster transition from less severe to more severe forms of SUD [8]. The earlier onset and increased use of substances in adolescents with ADHD compared with controls has been demonstrated in various retrospective [9] and prospective studies $[10,11]$. A meta-analysis of cohort studies has shown that childhood ADHD significantly increased the risk for nicotine use in middle adolescence and the risk for alcohol use disorder during young adulthood [12]. International research revealed large variance in the prevalence of comorbid ADHD in adult SUD patients $[13,14]$, which could only partly be explained by differences in ADHD assessment instruments [6]. An international multicenter, cross-sectional study in 10 countries (8 European countries, Australia, and the USA) found that more than $40 \%$ of the treatmentseeking SUD patients screened positive for ADHD, with DSM-IV adult ADHD prevalence rates ranging from $5.4 \%$ in Hungary to $31.3 \%$ in Norway [7]. While the mechanism associating ADHD with SUD remains unclear [15], family genetics, impulsive behavior, self-medication, and shared neuropsychological and biological pathways were offered as possible candidates [16-18].

Recent studies have established the clinical relevance of ADHD symptoms (impulsivity, disinhibition, executive function deficits, and slowed mental processing) for the prediction of SUD development and persistence $[19,20]$. These studies suggested that treatment outcomes for SUD may be improved by early and accurate identification and targeting ADHD symptoms in this population. Nevertheless, overlapping symptoms between ADHD and comorbid SUD represent challenges for diagnosis and treatment. Currently, no self-report ADHD scale has been sufficiently validated in a population with ADHD and SUD, and up to $20-40 \%$ of the patients with ADHD are missed when using a single screener [21-23]. The underreporting of ADHD symptoms by patients with SUD may reflect the cognitive deficits associated with both disorders, including limited mentalization abilities, underestimation of ADHD-related impairments, and difficulties in linking actual impairment with ADHD [24]. Diagnosing ADHD in adult patients with SUD requires the collection of retrospective information. However, this is often difficult to obtain because of the lack or inadequate anamnestic data $[25,26]$. Moreover, because the link between ADHD and SUD is usually investigated in treatment-seeking SUD patients, sociocultural influences on SUD treatment utilization may affect the likelihood that ADHD symptoms will be identified and reported [27-29].

Less frequent, but important, is the problem of overdiagnosing ADHD in SUD patients. Overdiagnosing can occur when substance-induced or withdrawal symptoms are erroneously perceived as ADHD symptoms or when the persistence of ADHD symptoms into adulthood is overlooked [30]. Thus, assessing ADHD symptoms using objective, easy-to-collect variables by noninvasive methods might be useful as a supportive measure in the detection and evaluation of comorbid ADHD and other neurological/psychiatric disorders in SUD patients [31].

\section{Using the CPT in the Assessment of ADHD}

Continuous performance tests (CPTs) are considered a key component of any ADHD assessment and are currently the most popular objective laboratory-based measures to support a clinical diagnosis of ADHD [32-34]. The majority of CPT tasks measure selective attention, sustained attention, and impulsivity [35-37] and can be used alongside clinical evaluation to inform the diagnostic process of ADHD [38, 39]. A typical CPT includes a serial presentation of visual or auditory target and nontarget stimuli (numbers, letters, or geometric figures) [35]. Response to nontarget stimuli is referred to as a "commission error" and is considered to measure impulsivity. The absence of response to target stimuli is referred to as an "omission error" and is assumed to measure inattention. Other standard measures include the number of correct responses, response time (RT), and variability in RT.

Several studies have supported the utility of the CPT in the diagnostic process of ADHD in children (see Hall et al. [39] for review). Research in adults, however, revealed that the CPT is sensitive to multiple conditions that involve central nervous system dysfunction, such as schizophrenia [40], mood disorders [41], and anxiety [42], but has low specificity for ADHD [43, 44].

Despite the popularity of the CPT in the diagnostic process of ADHD, only a few studies compared its utility to that of other laboratory-based tests in identifying ADHD. A meta-analysis by Nichols and Waschbusch [45] of the validity of laboratory cognitive tasks for ADHD, including the CPT, the Gordon Diagnostic System (GDS), the Children's Checking Task (CCT), the Delay of Gratification Tasks, the Choice-Delay Task (C-DT), and the Stop Signal Task (SST), supported the use of the SST, the C-DT, and the CPT for children with ADHD. Similarly, a study examining test-retest reliability of the CPT and the SST in children with ADHD found that the two tests yielded reliable measurements in ADHD children [46].

\section{The CPT and Substance Use}

Over the past 2 decades, many studies have focused on the relationship between acute and chronic substance use 
Fig. 1. PRISMA flow diagram of the study selection process. PRISMA, Preferred Reporting Items for Systematic Reviews and Meta-Analyses.

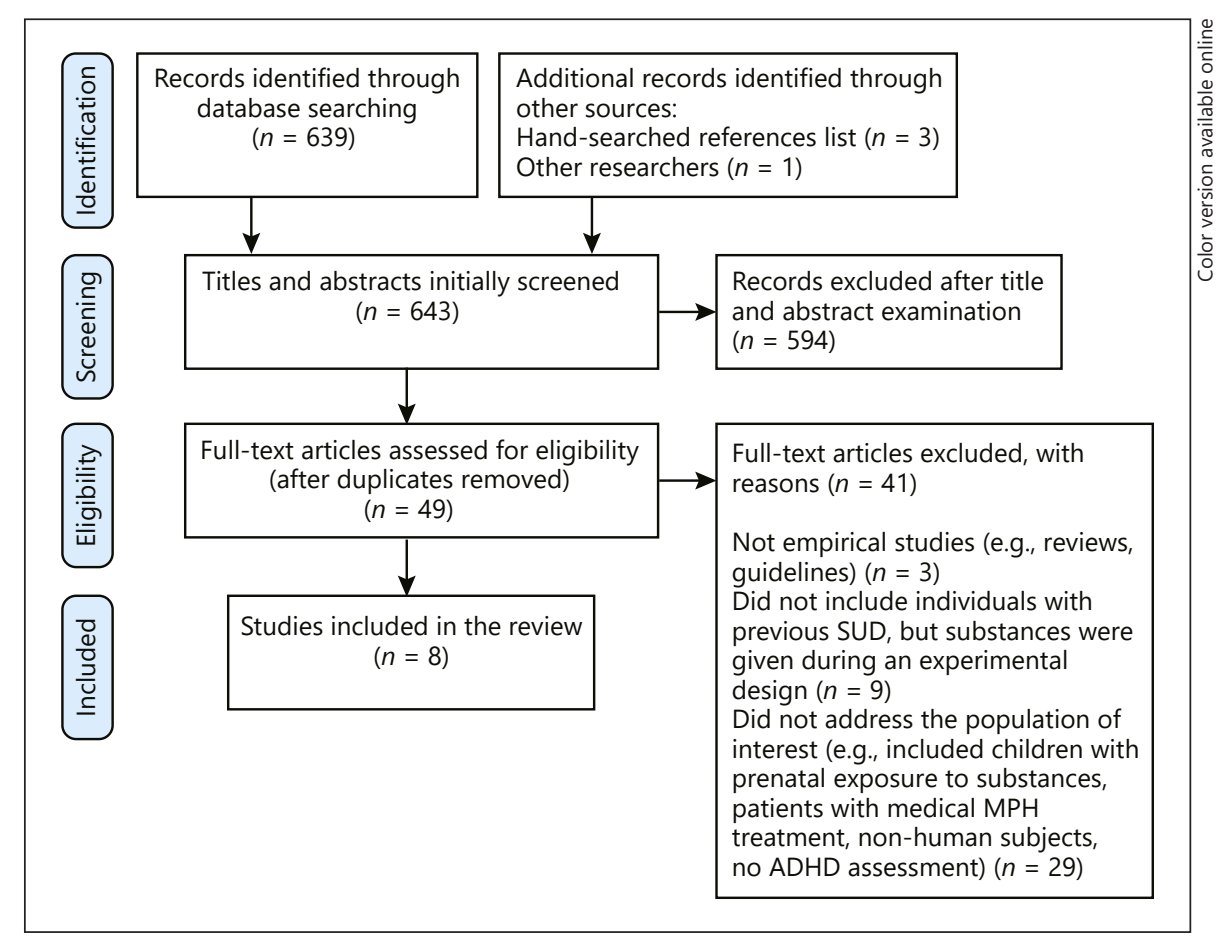

and cognitive functions, such as attention and response inhibition. Findings, however, were inconsistent. CPT impairment has been associated with chronic use of some substances, such as heroin [47] and cocaine [48], but not with alcohol [49] or nicotine [50, 51]. Differences between studies reflect methodological constraints (e.g., small samples) and variations in participants' age, severity, type of substance used, the use of extreme group designs (i.e., comparing control participants and problematic or disordered substance users) [52, 53], and different task requirement [54].

Importantly, while some studies examined the effects of chronic alcohol or nicotine use, others measured the acute and immediate effects of their administration. There is evidence to suggest that chronic smoking is associated with lower CPT performance [55], whereas nicotine administration is associated with improved CPT performance in both smokers and nonsmokers $[56,57]$.

Although patients with SUD may show similar attentional deficits to those observed in ADHD, data on the CPT performance of ADHD patients with comorbid SUD are currently very limited. Thus, it is difficult to conclude whether such a decreased performance reflects the comorbidity of ADHD or the cognitive deficits specific to SUD. As disinhibition control, impulsivity, and executive function deficits have been associated with worse sub- stance use outcomes [58-61], clarifying the specific cognitive profile of SUD with and without ADHD may be of significant clinical relevance.

\section{The Current Study}

Although research on the shared genetic, behavioral, and neurobiological correlates of ADHD and SUD is well established, there have been only a few studies comparing the cognitive profiles of the 2 disorders [62]. Several studies suggested that patients with comorbid ADHD and SUD may exhibit higher levels of impulsivity compared with either ADHD $[62,63]$ or SUD $[64,65]$ alone. However, others failed to find such differences [66]. The aim of this review is to directly examine the quantitative similarities and differences in CPT performance of adults with ADHD, SUD, and their comorbidity to determine if a distinct neurocognitive profile exists for each. To this aim, a systematic review of CPT studies involving adults with combined ADHD and SUD and a comparison group of one of the disorders alone was conducted using the Preferred Reporting Items for Systematic Reviews and Meta-Analyses (PRISMA) guidelines [67]. Given that both ADHD and SUD are associated with impaired attention functions, it was expected to find the most severe CPT deficits in adults with comorbid ADHD and SUD compared with either disorder alone. 


\section{Method}

Search Strategy and Inclusion Criteria

To locate studies for this review, PsycINFO, PubMed, and Google Scholar were searched. The search consisted of the terms "ADHD"/attention" and "Continuous Performance Test/CPT" with the following keywords: "substance use/substance use disorder/SUD," and/or "drug," and/or "addiction," and/or "cannabis," and/or "cocaine," and/or "amphetamine" and/or "heroin" and/or "nicotine," and/or "alcohol." Reference lists of studies were also searched to find other relevant articles. Retained studies had to meet 3 criteria. First, studies had to include empirical data. Second, studies had to include patients with comorbid ADHD and SUD and a comparison group of at least one of the disorders alone. Finally, studies had to include CPT results. No restriction was made on the date of publication, the language of publication, and the number of participants. Also, no restriction was made regarding the formal diagnosis of ADHD or SUD. In other words, participants were not obliged to meet the formal DSM-based criteria of ADHD or SUD. The search ended in March 2020.

\section{Data Extraction Strategy}

Figure 1 presents a PRISMA flow diagram of the study selection process. The database search identified 639 studies, searching for reference lists of reviews, and primary studies identified 3 additional studies. Contacting experts in the field revealed one more study. The screening phase involved examining the titles and abstracts of all 643 studies identified. This process resulted in 594 studies being excluded as they were deemed unsuitable for the present review.

Consequently, 49 studies were selected for the eligibility phase. Of these, 29 studies did not target the population of interest (i.e., adult patients with comorbid ADHD and SUD). These studies included children with prenatal exposure to substances, patients with ADHD that used methylphenidate $(\mathrm{MPH})$ for treating $\mathrm{AD}$ HD-related symptoms, and nonhuman subjects. Nine additional studies addressed the influence of substance use on CPT performance, but participants were given substances as part of the experimental design. Three more studies were review papers and not empirical studies. After removing these 41 articles, 8 articles were included in the review. All studies were inspected for their year of publication, sample size, substance type, and gender distribution. Cohen's $d$ was chosen as the common effect size.

\section{Results}

Eight studies met the review inclusion criteria. Table 1 provides an overview of the authors' names, publication year, sample size, gender distribution, substance type, CPT used, and diagnostic criteria of ADHD and SUD. Cohen's $d$ effect sizes are reported (Table 2) for the 4 studies that provided sufficient data for these to be calculated $[62,66,68,69]$.

\section{Sample Characteristics}

As seen, except for 1 study [66], all sample sizes were limited and ranged between 17 and 72 participants. All studies except $2[68,69]$ included more males than females (52-100\% males). Studies significantly differed in the substances used by participants, including nicotine ( 4 studies), morphine (1 study), cannabis (1 study), cocaine (2 studies), alcohol (1 study), and amphetamine (1 study). Three $[68,70,71]$ assessed both childhood and adult ADHD, while the rest included only adult ADHD.

\section{CPT Profiles of ADHD and SUD}

Table 2 presents CPT outcomes for all included studies. Study findings were integrated across the 4 key CPT indices: commission errors, which are considered a measure of impulsivity; omission errors, which indicate deficits in sustained attention; mean hit reaction time (RT), which measures response speed; and RT variability, which measures the inconsistency in response speed and fluctuations in attention [72-75].

\section{Commission Errors}

Four studies [68-70, 76] reported that the effect of substance use on the rate of commission errors differed between individuals with and without ADHD. Three of these studies addressed the effect of nicotine. Kollins et al. [76] found that the increase in commission errors on an abstinent day compared with a day after smoking as usual was nominally larger for smokers with ADHD than for smokers without ADHD, but the effect was not significant $(p=0.09)$. Similarly, McClernon et al. [68] found that smokers with ADHD made more commission errors than smokers without ADHD in the abstinent condition. Supporting the ameliorating effect of nicotine on commission errors in patients with comorbid ADHD, Rigbi et al. [69] found that nicotine administration strongly reduced the number of commission errors in ADHD patients with the highest levels of ADHD symptoms and impulsivity. There is also evidence that the presence of SUD in individuals with ADHD affected the rate of commission errors compared with patients with ADHD alone. Ginsberg et al. [70] found that inmate males with comorbidity of ADHD and SUD conducted more commission responses than psychiatric patients with ADHD alone. The 4 other studies $[62,66,71,77]$ did not find that the presence of ADHD in individuals with substance use was associated with different commission rates compared with individuals with either SUD or ADHD.

\section{Omission Errors}

Except for the study of Ginsberg et al. [70], which found that inmate males with comorbid ADHD and SUD made 
Table 1. A summary of the included studies

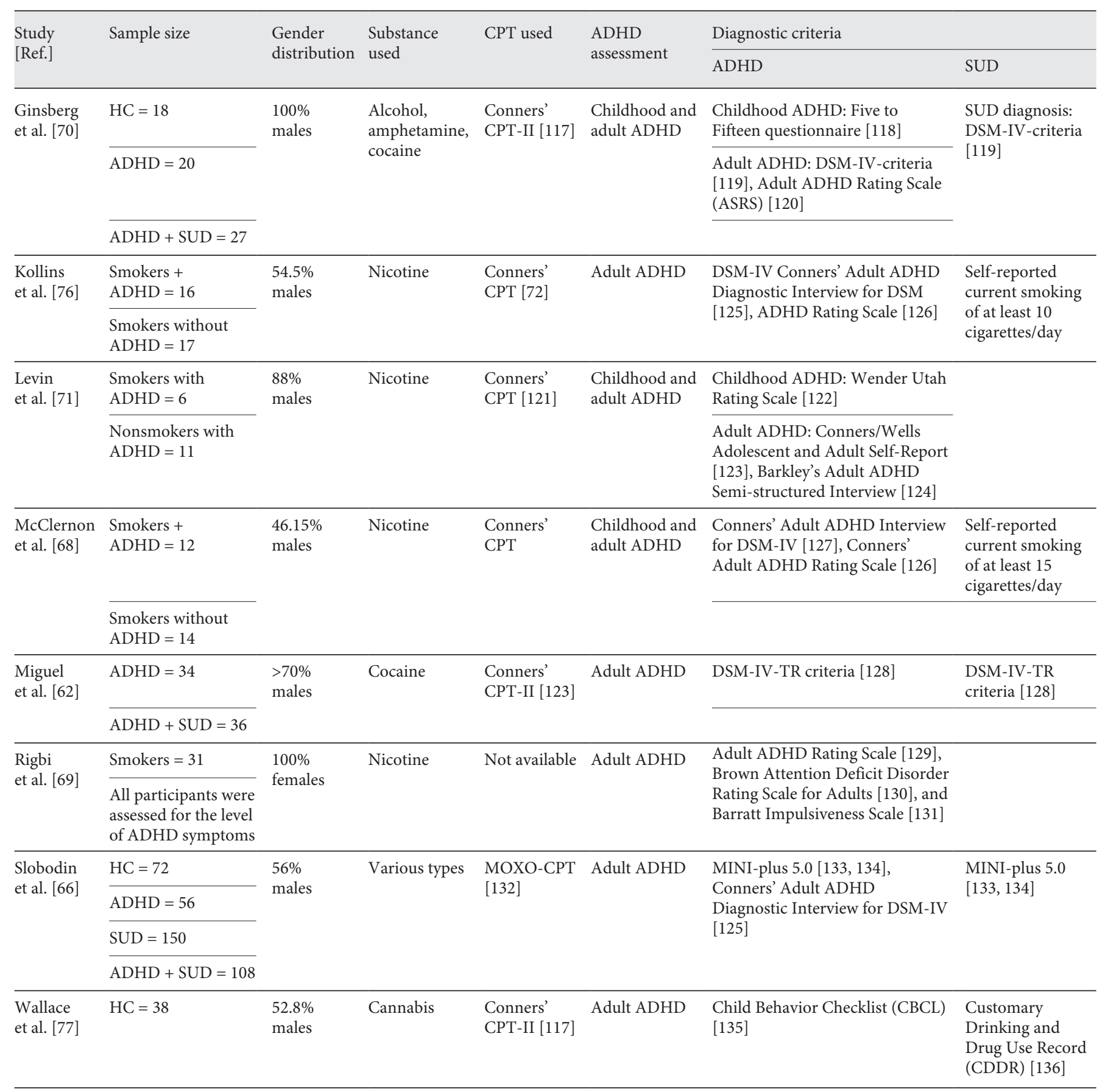

ADHD, attention-deficit/hyperactivity disorder; CPT, continuous performance test; HC, healthy control; SUD, substance use disorder.

more omission errors than psychiatric patients with $\mathrm{ADHD}$ alone, no study found differences in the rate of omission errors between patients with comorbid ADHD and SUD and patients with either ADHD $[62,66,71]$ or SUD $[66,68]$.

\section{RT Mean Hit and RT Variability}

Several studies reported that comorbidity of ADHD and SUD was associated with more deficits in RT variability and/or RT mean hit compared with patients with 


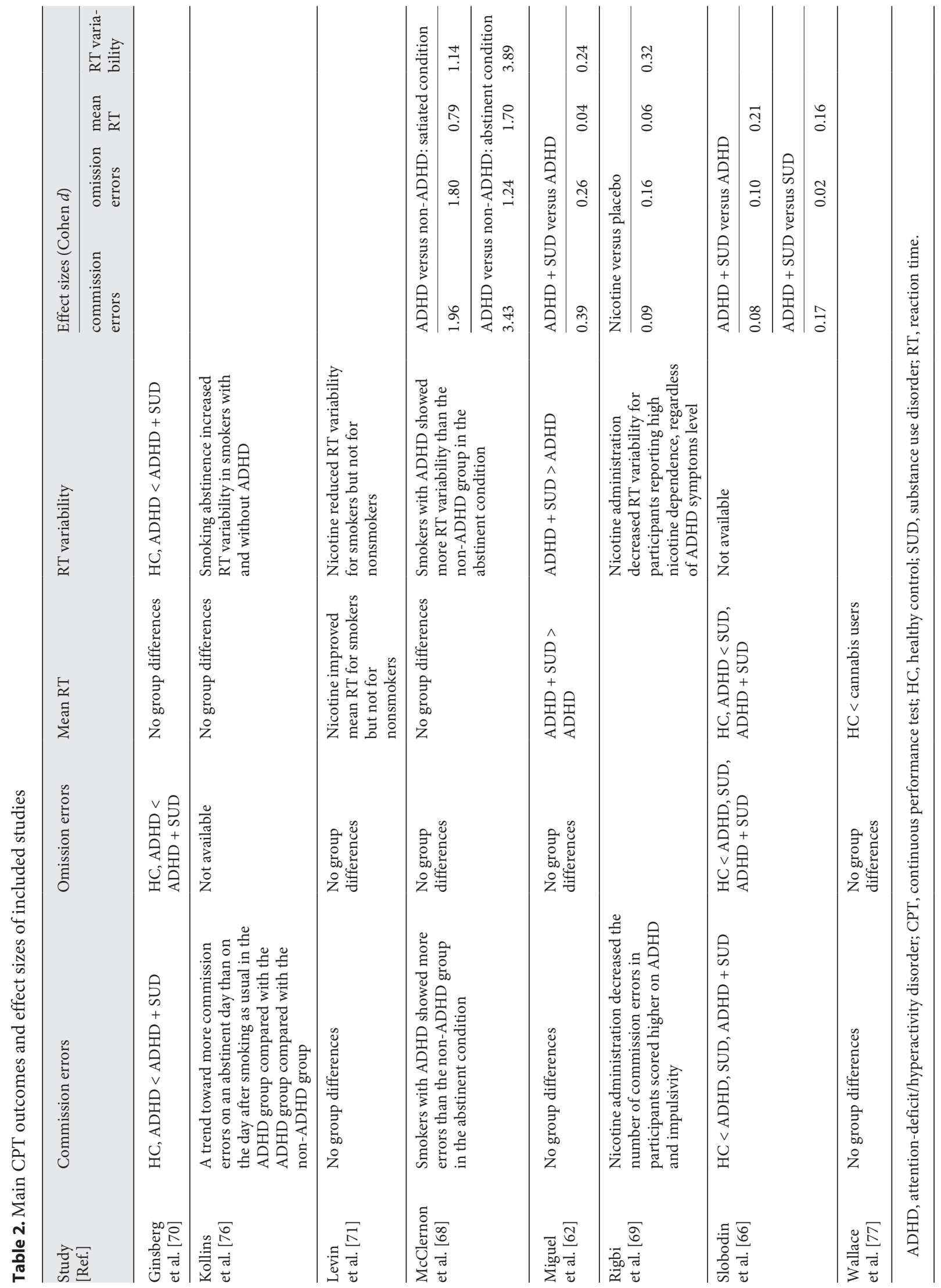


ADHD alone. Ginsberg et al. [70] found that while the ADHD group did not differ from the comorbidity group in the mean RT, RT variability was higher in the comorbidity group. Likewise, Miguel et al. [62] reported that cocaine-dependent patients with ADHD had longer RT and increased RT variability compared with individuals with ADHD alone. Finally, Slobodin et al. [66] found that patients with ADHD made more accurate and fast responses than participants with SUD and participants with both ADHD and SUD. This study also found that although patients with SUD and patients with comorbid ADHD and SUD showed impaired RT in comparison with healthy controls, no differences were found between the comorbid and the SUD-only groups. Similarly, Wallace et al. [77] reported that cannabis users demonstrated slower responses compared with controls, regardless of the level of ADHD symptoms.

The 4 studies that addressed the effects of nicotine use on RT mean and variability on individuals with and without ADHD showed inconsistent results [68, 69, 71, 76]. Levin et al. [71] demonstrated that nicotine has a facilitating effect on smokers' RT accuracy and variability so that smokers with ADHD showed a significant nicotine-induced speeding and reduced RT variability, whereas the nonsmokers with ADHD did not. Similarly, McClernon et al. [68] reported that smokers with ADHD demonstrated higher RT variability after overnight abstinence compared with smokers without ADHD. Nevertheless, the 2 other nicotine studies showed that the facilitating effect of nicotine on the cognitive performance of smokers was independent upon ADHD symptomatology $[69,76]$.

\section{Discussion}

Despite increasing awareness, ADHD still features as "hidden" comorbidity, often not diagnosed even in patients under psychiatric treatment for other psychiatric disorders [78]. In SUD patients, accurate identification of ADHD might be further complicated by cognitive and psychosocial problems that hinder individuals' ability to reflect upon their difficulties and report them [24-26].

This systematic review aimed to characterize differences and similarities in CPT performance of adults with ADHD, SUD, and their comorbidity. A literature search identified 8 eligible studies that included the measurement of ADHD in adults with SUD. Eligible studies covered a wide range of substance types, substance use severities, and study populations (inpatient, outpatients, inmates, and the general population). Overall, studies were limited in their total sample sizes, particularly in the proportion of females. Synthesis of results suggests that in terms of omission and commission errors, the comorbidity of ADHD and SUD was not necessarily associated with more deficits than either disorder alone. There was only one study that reported that individuals with comorbidity of ADHD and SUD conducted more commission and omission responses than psychiatric patients with ADHD alone [70]. According to this finding, SUD had an additive negative effect on the CPT performance of patients of ADHD. However, because the study compared $\mathrm{CPT}$ performance of long-term inmates diagnosed with both ADHD and SUD with high-functioning outpatients diagnosed with ADHD alone, it is difficult to isolate the influence of SUD from other cognitive, social, intellectual, and functional factors.

Examining the effects of nicotine on commission errors, Rigbi et al. [69] reported that nicotine administration decreased the number of commission errors with the stronger improvements in participants with more ADHD symptoms. In addition, nicotine was associated with improved RT means and decreased RT variability $[69,76$, 77], regardless of the presence of ADHD. These results provide some support for the self-medication hypothesis, which posits that individuals with ADHD may use nicotine to attenuate their symptoms $[17,20]$. Previous research suggested that as the typical ADHD psychostimulant medication $\mathrm{MPH}$, nicotine acts as an indirect dopamine agonist, improving attention and arousal and reducing impulsivity in individuals with $\operatorname{ADHD}[79,80]$.

While omission and commission rates are considered reliable indicators of ADHD in children [81, 82], in adults, these variables do not provide enough variability between individuals due to a ceiling effect in performance $[83,84]$. Therefore, the more typical outcome measure of most CPT variations is the variability of RT [72]. The current review identified 3 studies that reported that the comorbidity of ADHD and SUD was associated with more deficits in RT variability and/or RT mean hit compared with patients with ADHD alone [62, 66, 70]. Furthermore, 2 studies suggested that substance use negatively affected RT, regardless of ADHD [66, 77]. Together, these findings confirmed that inconsistency and variability are core cognitive symptoms associated with both ADHD [85-87] and SUD [88, 89]. However, the scarcity of research in this area does not allow us to draw a firm conclusion about whether both disorders have an additive effect on RT mean and variability.

Overall, the current review does not support the utility of the CPT in discriminating comorbid ADHD and SUD from either disorder alone. Included studies suggest that 
while the CPT might be sensitive to attentional deficits, such as disinhibition, impulsivity, and response speed, it lacks specificity for the diagnosis of adult ADHD, SUD, or their comorbidity. This finding is in contrast to previous studies that found that when ADHD co-occurred with other psychiatric disorders, such as autism syndrome disorder [90] or depression [91], CPT performance was worse compared with ADHD alone. One possible explanation for this discrepancy is that the neurobiological and behavioral similarities between ADHD and SUD (e.g., deficits in attention and working memory, slowed mental processing, and impulsivity) are larger than the similarities between ADHD and other psychiatric disorders. It is also possible that because many individuals with ADHD start to use substance early, it is difficult to disentangle the independent impact of SUD on cognition [92]. As ADHD is associated with developmental delays [93, 94], some of them are evident in the CPT $[95,96]$, the additional impact of SUD on CPT performance was difficult to detect. Finally, the lack of consistent differences between the cognitive profiles of ADHD and SUD may also be attributed to the history of ADHD diagnosis. It has been suggested that premorbid childhood ADHD diagnosis is associated with more significant attention deficits, compared with current ADHD symptoms [77]. The fact that only 2 included studies addressed childhood ADHD [70, 71] may explain why the current review failed to identify consistent differences between the cognitive profiles of patients with and without ADHD.

Finally, it should be noted that although the CPT is currently the most popular objective measure of ADHDrelated symptoms, other neurocognitive paradigms, such as the Go/No-Go (GNG) task and the SST, showed sensitivity to attention and inhibition deficits in chronic substance users (e.g., $[53,68,97]$ ) and following drug administration (e.g., [98]). Despite observed similarities, these paradigms capture different functions of attention and inhibition [99]. However, their advantage over the CPT in identifying ADHD in individuals with SUD remains unclear $[50,68]$.

Interpretation of findings involving patients with ADHD, SUD, or both entails the distinction between the diagnoses of ADHD/SUD and their classifications. Diagnostic criteria are a set of signs, symptoms, and tests that reflect the heterogeneous features of a disease $[100,101]$. Classification criteria, on the other hand, are standardized definitions that are primarily aimed at establishing well-defined, relatively homogenous cohorts for clinical research. If sufficient internal and external validity for diagnosis is demonstrated in a given population, classifica- tion criteria can be diagnostic. However, because disease features are not typically identical among patients with a given disease, meeting classification criteria is not equivalent to carrying a given diagnosis $[101,102]$.

The findings of this systematic review should be considered under certain limitations. First, the studies described here were not always comparable because of important differences in methodologies. For instance, while some studies included patients with a formal DSM-based diagnosis of ADHD and SUD, others used self-report measures. Second, most studies have been performed in small samples, almost all of them under 100 participants. Third, due to the cross-sectional nature of all studies, it was impossible to determine the timing and causality of the ADHD symptomology, SUD, and cognitive performance. Prospective CPT studies will enable us to examine whether and how ADHD symptoms predispose SUD and will enhance the development of specific interventions. Fourth, due to the shortage of studies and insufficient information, it was impossible to analyze findings regarding ADHD presentations. As ADHD presentations were found to be associated with both CPT performance [103] and substance abuse [104], further investigation is warranted.

There is also a need to explore the utility of other CPT measures, including distractibility and hyperactivity, in discriminating ADHD, SUD, and their comorbidity. There is evidence that the number of hyperactive responses during CPT performance distinguished between individuals with ADHD (with or without comorbid SUD) and individuals with SUD alone (hyperactivity was higher in the ADHD group and the comorbid group) [66]. This finding is consistent with previous studies that identified motor activity as the most predictive marker of ADHD [105, 106], thus emphasizing the importance of extending our investigation to other cognitive functions.

\section{Conclusions}

This review highlights the shortage of large-scale CPT research involving patients with ADHD and SUD. It is, therefore, impossible to determine whether the presence of ADHD in individuals with SUD is associated with decreased cognitive performance or whether both disorders have an additive effect on the CPT.

Early identification of ADHD in individuals with SUD is important because $\mathrm{ADHD}$ has an adverse effect on the development and course of SUD. A failure to diagnose ADHD poses significant sociocultural, educational, em- 
ployment, relationship, and coping deficits $[107,108]$ and increases the risk for additional comorbidities [109]. Diagnosis of ADHD is also important because it is often accompanied by recommendations for intervention [110]. The pharmacological treatment of ADHD has been a source of controversy [111, 112]. Several researchers showed that individuals with ADHD and SUD experience positive treatment effects regarding both $\mathrm{ADHD}$ and SUD-related outcomes $[113,114]$. However, it has also been noted that ADHD treatment may not be as effective in individuals with active SUD [64], partly due to drug-induced changes in the brain and similarities in the mechanism of action between stimulant medication and abused substances [115].

The International Consensus Statement on Screening, Diagnosis and Treatment of SUD patients with comorbid ADHD recommended that the diagnostic process of ADHD in SUD patients should be started as soon as possible, given that are no serious withdrawal symptoms or intoxication [30]. A prospective test-retest study of adults with ADHD and SUD [116] showed that most of them (95.3\%) still fulfilled DSM-IV adult ADHD criteria at reevaluation 2-3 months later, indicating that active substance use should not prevent a diagnostic evaluation.

An important direction for future CPT studies may be to explore whether specific attentional deficits among pa- tients with SUD accounts for their increased risk for treatment failure. Identifying which cognitive deficits are most relevant to SUD may contribute to the development of possible intervention approaches.

\section{Statement of Ethics}

Ethics approval was not required for the current literature review (in consultation with the ethics committee of the Department of Education, Ben-Gurion University).

\section{Disclosure Statement}

The author declares no conflicts of interest.

\section{Funding Sources}

The author did not receive any funding.

\section{Author Contributions}

O.S. was the only author of this manuscript and was responsible for data search, analysis, and writing the manuscript.

\section{References}

1 Centers for Disease Control, Prevention (CDC). Attention-Deficit/Hyperactivity Disorder (ADHD). Available from: https://www. cdc.gov/ncbddd/adhd/index.html.

2 Erskine HE, Norman RE, Ferrari AJ, Chan GC, Copeland WE, Whiteford HA, et al. Long-term outcomes of attention-deficit/hyperactivity disorder and conduct disorder: a systematic review and meta-analysis. J Am Acad Child Adolesc Psychiatry. 2016; 55(10):841-50.

3 JJS Kooij, Bijlenga D, Salerno L, Jaeschke R, Bitter I, Balázs J, et al. Updated European Consensus Statement on diagnosis and treatment of adult ADHD. Eur Psychiatry. 2019; $56: 14-34$.

4 Faraone SV, Biederman J, Mick E. The agedependent decline of attention deficit hyperactivity disorder: a meta-analysis of follow-up studies. Psychol Med. 2006;36(2):159-65.

5 Notzon DP, Pavlicova M, Glass A, Mariani JJ, Mahony AL, Brooks DJ, et al. ADHD is highly prevalent in patients seeking treatment for cannabis use disorders. J Atten Disord. 2016:1087054716640109.
6 van de Glind G, Van Emmerik-van Oortmerssen K, Carpentier PJ, Levin FR, Koeter MW, Barta C, et al. The International ADHD in Substance Use Disorders Prevalence (IASP) study: background, methods and study population. Int $\mathrm{J}$ Methods Psychiatr Res. 2013;22(3):232-44.

7 van de Glind G, Konstenius M, Koeter MWJ, van Emmerik-van Oortmerssen K, Carpentier PJ, Kaye S, et al. Variability in the prevalence of adult ADHD in treatment seeking substance use disorder patients: results from an international multi-center study exploring DSM-IV and DSM-5 criteria. Drug Alcohol Depend. 2014;134:158-66.

8 Fatséas M, Hurmic H, Serre F, Debrabant R, Daulouède JP, Denis C, et al. Addiction severity pattern associated with adult and childhood attention deficit hyperactivity disorder (ADHD) in patients with addictions. Psychiatry Res. 2016;246:656-62.

9 Ohlmeier MD, Peters K, Te Wildt BT, Zedler M, Ziegenbein M, Wiese B, et al. Comorbidity of alcohol and substance dependence with attention-deficit/hyperactivity disorder (ADHD). Alcohol Alcohol. 2008;43(3): 300-4.
10 Groenman AP, Janssen TWP, Oosterlaan J. Childhood psychiatric disorders as risk factor for subsequent substance abuse: a meta-analysis. J Am Acad Child Adolesc Psychiatry. 2017;56(7):556-69.

11 Lee SS, Humphreys KL, Flory K, Liu R, Glass K. Prospective association of childhood attention-deficit/hyperactivity disorder (ADHD) and substance use and abuse/dependence: a meta-analytic review. Clin Psychol Rev. 2011; 31(3):328-41.

12 Charach A, Yeung E, Climans T, Lillie E. Childhood attention-deficit/hyperactivity disorder and future substance use disorders: comparative meta-analyses. J Am Acad Child Adolesc Psychiatry. 2011;50(1):9-21.

13 Van Emmerik-van Oortmerssen K, Van de Glind G, Van den Brink W, Smit F, Crunelle CL, Swets M, et al. Prevalence of attentiondeficit hyperactivity disorder in substance use disorder patients: a meta-analysis and metaregression analysis. Drug Alcohol Depend. 2011;122(1-2):11-9.

14 Umar MU, Salihu AS, Owolabi SD. Prevalence and correlates of ADHD in individuals with substance use disorder in Nigeria. Atten Defic Hyperact Disord. 2017;9:189-98. 
15 Kollins SH, Sweitzer MM, McClernon FJ, Perkins KA. Increased subjective and reinforcing effects of initial nicotine exposure in young adults with attention deficit hyperactivity disorder (ADHD) compared to matched peers: results from an experimental model of first-time tobacco use. Neuropsychopharmacology. 2019;45(5):851-6.

16 Faraone SV, Larsson H. Genetics of attention deficit hyperactivity disorder. Mol Psychiatry. 2019;24(4):562-75.

17 Ortal S, van de Glind G, Johan F, Itai B, Nir Y, Iliyan I, et al. The role of different aspects of impulsivity as independent risk factors for substance use disorders in patients with ADHD: a review. Curr Drug Abuse Rev. 2015; 8(2):119-33.

18 Wilens T, Adamson J, Sgambati S, Whitley J, Santry A, Monuteaux M, et al. Do individuals with ADHD self-medicate with cigarettes and substances of abuse? Results from a controlled family study of ADHD. Am J Addict. 2007;16(Suppl 1):14-23.

19 Elkins IJ, Saunders GRB, Malone SM, Keyes MA, Samek DR, McGue M, et al. Increased risk of smoking in female adolescents who had childhood ADHD. Am J Psychiatry. 2018; 175:appiajp201717010009.

20 van Amsterdam J, van der Velde B, Schulte M, van den Brink W. Causal factors of increased smoking in ADHD: a systematic review. Subst Use Misuse. 2018;53:1-14.

21 Bastiaens L, Galus J: Comparison of the adult ADHD self report scale screener for DSM-IV and DSM-5 in a dually diagnosed correctional population. Psychiatr Q. 2018;89(2):50510.

22 Dakwar E, Mahony A, Pavlicova M, Glass A, Brooks D, Mariani JJ, et al. The utility of attention-deficit/hyperactivity disorder screening instruments in individuals seeking treatment for substance use disorders. J Clin Psychiatry. 2012;73(11):e1372-8.

23 Luderer M, Kaplan-Wickel N, Richter A, Reinhard I, Kiefer F, Weber T. Screening for adult attention-deficit/hyperactivity disorder in alcohol dependent patients: underreporting of ADHD symptoms in self-report scales. Drug Alcohol Depend. 2019;195:52-8.

24 Levin FR, Upadhyaya HP: Diagnosing ADHD in adults with substance use disorder: DSMIV criteria and differential diagnosis. J Clin Psychiatry. 2007;68(7):e18.

25 Faraone S, Wilens T, Petty C, Antshel K, Spencer T, Biederman J. Substance use among ADHD adults: implications of late onset and subthreshold diagnoses. Am J Addict. 2007; 16(Suppl 1):24-34.

26 Sullivan MA. Rudnik-Levin F, Rudnik-Levin F. Attention deficit/hyperactivity disorder and substance abuse. Diagnostic and therapeutic considerations. Ann N Y Acad Sci. 2001;931:251-70.

27 Slobodin O, Crunelle CL. Mini review: sociocultural influences on the link between ADHD and SUD. Front Public Health. 2019; $7: 173$
28 Acevedo A, Garnick DW, Lee MT, Horgan CM, Ritter G, Panas L, et al. Racial and ethnic differences in substance abuse treatment initiation and engagement. J Ethn Subst Abuse. 2012;11(1):1-21.

29 Arfken CL, Kubiak SP, Farrag M. Acculturation and polysubstance abuse in Arab-American treatment clients. Transcult Psychiatry. 2009;46(4):608-22.

30 Crunelle CL, van den Brink W, Moggi F, Konstenius M, Franck J, Levin FR, et al. International consensus statement on screening, diagnosis and treatment of substance use disorder patients with comorbid attention deficit/ hyperactivity disorder. Eur Addict Res. 2018; 24(1):43-51.

$31 \mathrm{Na}$ KS. Prediction of future cognitive impairment among the community elderly: a machine-learning based approach. Sci Rep. 2019; 9(1):3335

32 Edwards MC, Gardner ES, Chelonis JJ, Schulz EG, Flake RA, Diaz PF. Estimates of the validity and utility of the Conners' Continuous Performance Test in the assessment of inattentive and/or hyperactive-impulsive behaviors in children. J Abnorm Child Psychol. 2007;35(3):393-404

33 Vogt C, Williams T. Early identification of stimulant treatment responders, partial responders and non-responders using objective measures in children and adolescents with hyperkinetic disorder. Child Adolesc Ment Health. 2011;16(3):144-9.

34 Fuermaier ABM, Fricke JA, de Vries SM, Tucha L, Tucha O. Neuropsychological assessment of adults with ADHD: a Delphi consensus study. Appl Neuropsychol Adult. 2019; 26(4):340-54

35 Conners C. Conners' continuous performance test II: computer program for windows technical guide and software manual. North Tonawanda, NY: Multi-Health Systems; 2000.

36 Greenberg LMTOV. A visual continuous performance 15. test. Los Alamitos, CA: Universal Attention Disorders Inc; 1997.

37 Gordon M, Mettelman B. Technical guide to the Gordon diagnostic system. Syracuse, NY: Gordon Systems; 1987

38 Hall CL, Walker GM, Valentine AZ, Guo B, Kaylor-Hughes C, James M, et al. Protocol investigating the clinical utility of an objective measure of activity and attention (QbTest) on diagnostic and treatment decision-making in children and young people with ADHD"Assessing QbTest Utility in ADHD" (AQUA): a randomised controlled trial. BMJ Open. 2014;4(12):e006838.

39 Hall CL, Valentine AZ, Groom MJ, Walker GM, Sayal K, Daley D, et al. The clinical utility of the continuous performance test and objective measures of activity for diagnosing and monitoring ADHD in children: a systematic review. Eur Child Adolesc Psychiatry. 2016;25(7):677-99.

40 Nuechterlein $\mathrm{KH}$, Green MF, Calkins ME, Greenwood TA, Gur RE, Gur RC, et al. Attention/vigilance in schizophrenia: performance results from a large multi-site study of the Consortium on the Genetics of Schizophrenia (COGS). Schizophr Res. 2015;163(1-3):3846.

41 Sommerfeldt SL, Cullen KR, Han G, Fryza BJ, Houri AK, Klimes-Dougan B. Executive attention impairment in adolescents with major depressive disorder. J Clin Child Adolesc Psychol. 2016;45(1):69-83.

42 Cuffe SP, McCullough EL, Pumariega AJ. Comorbidity of attention deficit hyperactivity disorder and post-traumatic stress disorder. J Child Fam Stud. 1994;3(3):327-36.

43 Riccio CA, Reynolds CR. Continuous performance tests are sensitive to ADHD in adults but lack specificity. A review and critique for differential diagnosis. Ann N Y Acad Sci. 2006;931:113-39.

44 Advokat C, Lane SM, Luo C. College students with and without ADHD: comparison of selfreport of medication usage, study habits, and academic achievement. J Atten Disord. 2011 15:656-66.

45 Nichols S, Waschbusch D. A review of the validity of laboratory cognitive tasks used to assess symptoms of ADHD. Child Psychiatry Hum Dev. 2004:34:297-315.

46 Soreni N, Crosbie J, Ickowicz A, Schachar R Stop signal and Conners' continuous performance tasks: test-retest reliability of two inhibition measures in ADHD children. J Atten Disord. 2009; 13:137-43.

47 Sarkissians S, Hauson A, Stelmach N, Walker A, Pollard A, Barlet B, et al. A-09 attention in individuals with heroin dependence measured by digit span versus continuous performance test. Arch Clin Neuropsychol. 2019; 34(6):868.

48 Gooding DC, Burroughs S, Boutros NN. Attentional deficits in cocaine-dependent patients: converging behavioral and electrophysiological evidence. Psychiatry Res. 2008, 160(2):145-54

49 Koelega HS. Alcohol and vigilance performance: a review. Psychopharmacology. 1995; 118(3):233-49.

50 Dinur-Klein L, Kertzman S, Rosenberg O, Kotler M, Zangen A, Dannon PN. Response inhibition and sustained and attention in heavy smokers versus non-smokers. Isr J Psychiatry Relat Sci. 2014:51(4):240-6.

51 Myers CS, Taylor RC, Salmeron BJ, Waters AJ, Heishman SJ. Nicotine enhances alerting, but not executive, attention in smokers and nonsmokers. Nicotine Tob Res. 2013; 15(1):277-81.

52 Kreusch F, Quertemont E, Vilenne A, Hansenne M. Alcohol abuse and ERP components in Go/No-go tasks using alcohol-related stimuli: impact of alcohol avoidance. Int J Psychophysiol. 2014;94(1):92-9.

53 Liu Y, van den Wildenberg WPM, de Graaf Y, Ames SL, Baldacchino A, Bø R, et al. Is (poly) substance use associated with impaired inhibitory control? A mega-analysis controlling for confounders. Neurosci Biobehav Rev. 2019;105:288-304 
54 Dougherty DM, Marsh DM, Moeller FG, Chokshi RV, Rosen VC. Effects of moderate and high doses of alcohol on attention, impulsivity, discriminability, and response bias in immediate and delayed memory task performance. Alcohol Clin Exp Res. 2000; 24(11):1702-11.

55 Wing VC, Bacher I, Sacco KA, George TP. Neuropsychological performance in patients with schizophrenia and controls as a function of cigarette smoking status. Psychiatry Res. 2011;188(3):320-6.

56 Barr RS, Culhane MA, Jubelt LE, Mufti RS, Dyer MA, Weiss AP, et al. The effects of transdermal nicotine on cognition in nonsmokers with schizophrenia and nonpsychiatric controls. Neuropsychopharmacology. 2008;33 (3):480-90.

57 Dépatie L, O’Driscoll GA, Holahan AL, Atkinson V, Thavundayil JX, Kin NN, et al. Nicotine and behavioral markers of risk for schizophrenia: a double-blind, placebo-controlled, cross-over study. Neuropsychopharmacology. 2002;27(6):1056-70.

58 Levin FR, Evans SM, Vosburg SK, Horton T, Brooks D, Ng J. Impact of attention-deficit hyperactivity disorder and other psychopathology on treatment retention among cocaine abusers in a therapeutic community. Addict Behav. 2004;29(9):1875-82.

59 Rømer Thomsen K, Callesen MB, Hesse M, Kvamme TL, Pedersen MM, Pedersen MU, et al. Impulsivity traits and addiction-related behaviors in youth. J Behav Addict. 2018; 7(2):317-30.

60 Tarter RE, Kirisci L, Mezzich A,, Cornelius JR, Pajer K, Vanyukov M, et al. Neurobehavioral disinhibition in childhood predicts early age at onset of substance use disorder. Am J Psychiatry. 2003;160(6):1078-85.

61 Deckel AW, Hesselbrock V. Behavioral and cognitive measurements predict scores on the MAST: a 3-year prospective study. Alcohol Clin Exp Res. 1996;20(7):1173-8.

62 Miguel CS, Martins PA, Moleda N, Klein M, Chaim-Avancini T, Gobbo MA, et al. Cognition and impulsivity in adults with attention deficit hyperactivity disorder with and without cocaine and/or crack dependence. Drug Alcohol Depend. 2016;160:97-104.

63 Crunelle CL, Veltman DJ, van Emmerik-van Oortmerssen K, Booij J, van den Brink W. Impulsivity in adult ADHD patients with and without cocaine dependence. Drug Alcohol Depend. 2013;129(1-2):18-24.

64 Pérez de Los Cobos J, Siñol N, Puerta C, Cantillano V, López Zurita C, Trujols J. Features and prevalence of patients with probable adult attention deficit hyperactivity disorder who request treatment for cocaine use disorders. Psychiatry Res. 2011;185(1-2):205-10.

65 Stevens L, Roeyers H, Dom G, Joos L, Vanderplasschen W. Impulsivity in cocaine-dependent individuals with and without attentiondeficit/hyperactivity disorder. Eur Addict Res. 2015;21(3):131-43.
66 Slobodin O, Blankers M, Kapitány-Fövény M, Kaye S, Berger I, Johnson B, et al. Differential diagnosis in patients with substance use disorder and/or attention-deficit/hyperactivity disorder using continuous performance test. Eur Addict Res. 2020;26(3):151-62.

67 D Moher, Liberati A, Tetzlaff J, Altman DG; PRISMA Group. Preferred reporting items for systematic reviews and meta-analyses: the PRISMA statement. Int J Surg. 2009;8(5):336-41.

68 McClernon FJ, Kollins SH, Lutz AM, Fitzgerald DP, Murray DW, Redman C, et al. Effects of smoking abstinence on adult smokers with and without attention deficit hyperactivity disorder: results of a preliminary study. Psychopharmacology. 2008;197(1):95-105.

69 Rigbi A, Yakir A, Sarner-Kanyas K, Pollak Y, Lerer B. Why do young women smoke? VI. A controlled study of nicotine effects on attention: pharmacogenetic interactions. Pharmacogenomics J. 2011;11(1):45-52.

70 Ginsberg Y, Hirvikoski T, Lindefors N. Attention deficit hyperactivity disorder (ADHD) among longer-term prison inmates is a prevalent, persistent and disabling disorder. BMC Psychiatry. 2010;10:112.

71 Levin ED, Conners CK, Sparrow E, Hinton SC, Erhardt D, Meck WH, et al. Nicotine effects on adults with attention-deficit/hyperactivity disorder. Psychopharmacology. 1996; 123(1):55-63.

72 Conners C. The Conners' continuous performance test. 2. North Tonawanda, NY: MultiHealth Systems; 2000.

73 Murphy KR, Barkley RA, Bush T. Executive functioning and olfactory identification in young adults with attention deficit-hyperactivity disorder. Neuropsychology. 2001; 15(2):211-20

74 Shalev N, Humphreys G, Demeyere N. Manipulating perceptual parameters in a continuous performance task. Behav Res Methods. 2018;50:380-91.

75 Kofler MJ, Rapport MD, Sarver DE, Raiker JS, Orban SA, Friedman LM, et al. Reaction time variability in ADHD: a meta-analytic review of 319 studies. Clin Psychol Rev. 2013; 33(6):795-811.

76 Kollins SH, English JS, Roley ME, O’Brien B, Blair J, Lane SD, et al. Effects of smoking abstinence on smoking-reinforced responding, withdrawal, and cognition in adults with and without attention deficit hyperactivity disorder. Psychopharmacology. 2013;227(1):19-30.

77 Wallace AL, Wade NE, Hatcher KF, Lisdahl KM. Effects of cannabis use and subclinical ADHD symptomology on attention based tasks in adolescents and young adults. Arch Clin Neuropsychol. 2019;34(5):700-5.

78 Bitter I, Mohr P, Balogh L, Látalová K, Kakuszi B, Stopková P, et al. ADHD: a hidden comorbidity in adult psychiatric patients. Atten Defic Hyperact Disord. 2019;11(1):83-9.

79 De BM, Dani JA. Reward, addiction, withdrawal to nicotine. Ann Rev Neurosci. 2011; 34:105-30.
80 Volkow ND, Fowler JS, Wang GJ, Baler R, Telang F. Imaging dopamine's role in drug abuse and addiction. Neuropharmacology. 2009;56(Suppl 1):3-8.

81 Berger I, Slobodin O, Cassuto H. Usefulness and validity of continuous performance tests in the diagnosis of attention-deficit hyperactivity disorder children. Arch Clin Neuropsychol. 2017;32(1):81-93.

82 Epstein JN, Erkanli A, Conners CK, Klaric J, Costello JE, Angold A. Relations between continuous performance test performance measures and ADHD behaviors. J Abnorm Child Psychol. 2003;31(5):543-54.

83 Halperin JM, Sharma V, Greenblatt E, Schwartz ST. Assessment of the continuous performance test: reliability and validity in a nonreferred sample. Psychol Assess. 1991; 3(4):603-8.

84 Robertson IH, Ridgeway V, Greenfield E, Parr A. Motor recovery after stroke depends on intact sustained attention: a 2-year follow-up study. Neuropsychology. 1997;11(2):290-5.

85 Hervey AS, Epstein JN, Curry JF, Tonev S, Eugene Arnold L, Keith Conners C, et al . Reaction time distribution analysis of neuropsychological performance in an ADHD sample. Child Neuropsychol. 2006;12(2):125-40.

86 McGee RA, Clark SE, Symons DK. Does the Conners' continuous performance test aid in ADHD diagnosis? J Abnorm Child Psychol. 2000;28(5):415-24.

87 Perry GM, Sagvolden T, Faraone SV. Intraindividual variability in genetic and environmental models of attention-deficit/hyperactivity disorder. Am J Med Genet B Neuropsychiatr Genet. 2010;153B(5):1094-101.

88 Liu S, Lane SD, Schmitz JM, Green CE, Cunningham KA, Moeller FG. Increased intraindividual reaction time variability in cocaine-dependent subjects: role of cocaine-related cues. Addict Behav. 2012;37(2):193-7.

89 Jones A, Tiplady B, Houben K, Nederkoorn C, Field M. Do daily fluctuations in inhibitory control predict alcohol consumption? An ecological momentary assessment study. Psychopharmacology. 2018;235(5):1487-96.

90 Lundervold AJ, Stickert M, Hysing M, Sørensen L, Gillberg C, Posserud MB. Attention deficits in children with combined autism and ADHD: a CPT study. J Atten Disord. 2016; 20(7):599-609.

91 Armengol CG. Effect of co-morbid depression on continuous performance test (CPT) tasks in college students with attention deficit hyperactivity disorder (ADHD). Facultad de Psicología: Departamento de Psicología Exp, 2003. Retrieved from https://dialnet.unirioja. es/servlet/articulo? codigo $=1127463$.

92 Tamm L, Epstein JN, Lisdahl KM, Molina B, Tapert S, Hinshaw SP, et al. Impact of ADHD and cannabis use on executive functioning in young adults. Drug Alcohol Depend. 2013; 133(2):607-14. 
93 Shaw P, Eckstrand K, Sharp W, Blumenthal J, Lerch JP, Greenstein D, et al. Attention-deficit/hyperactivity disorder is characterized by a delay in cortical maturation. Proc Natl Acad Sci U S A. 2007;104(49):19649-54.

94 Shaw P, Malek M, Watson B, Sharp W, Evans A, Greenstein D. Development of cortical surface area and gyrification in attentiondeficit/hyperactivity disorder. Biol Psychiatry. 2012;72(3):191-7.

95 Berger I, Slobodin O, Aboud M, Melamed J, Cassuto H. Maturational delay in ADHD: evidence from CPT. Front Hum Neurosci. 2013;7(7):691.

96 Slobodin O, Cassuto H, Berger I. Age-related changes in distractibility: developmental trajectory of sustained attention in ADHD. J Atten Disord. 2018;22:1333-43.

97 Spinella M. Correlations between orbitofrontal dysfunction and tobacco smoking. Addict Biol. 2002;7(4):381-4.

98 Marczinski CA, Fillmore MT. Dissociative antagonistic effects of caffeine on alcoholinduced impairment of behavioral control. Exp Clin Psychopharmacol. 2003;11(3):22836.

99 Lijffijt M, Kenemans JL, Verbaten MN, van Engeland H. A meta-analytic review of stopping performance in attention-deficit/hyperactivity disorder: deficient inhibitory motor control? J Abnorm Psychol. 2005; 114(2):216-22.

100 McKeown T. A basis for health strategies. A classification of disease. Br Med J. 1983; 287(6392):594-6.

101 Aggarwal R, Ringold S, Khanna D, Neogi T, Johnson SR, Miller A, et al. Distinctions between diagnostic and classification criteria? Arthritis Care Res. 2015;67(7):891-7.

102 Yazici H. Diagnostic versus classification criteria: a continuum. Bull NYU Hosp Jt Dis. 2009;67(2):206-8.

103 Tucha O, Walitza S, Mecklinger L, Sontag TA, Kübber S, Linder M, et al. Attentional functioning in children with ADHD: predominantly hyperactive-impulsive type and children with ADHD: combined type. J Neural Transm. 2006;113(12):1943-53.

104 Liebrenz M, Gamma A, Ivanov I, Buadze A, Eich D. Adult attention-deficit/hyperactivity disorder: associations between subtype and lifetime substance use: a clinical study. F1000Res. 2016;4:407.

105 Lis S, Baer N, Stein-en-Nosse C, Gallhofer B, Sammer G, Kirsch P: Objective measurement of motor activity during cognitive performance in adults with attention-deficit/ hyperactivity disorder. Acta Psychiatr Scand. 2010;122(4):285-94.

106 Teicher MH, Polcari A, Fourligas N, Vitaliano G, Navalta CP. Hyperactivity persists in male and female adults with ADHD and remains a highly discriminative feature of the disorder: a case-control study. BMC Psychiatry. 2012;12:190

107 Faraone SV, Sergeant J, Gillberg C, Biederman J. The worldwide prevalence of ADHD: is it an American condition? World Psychiatry. 2003;2(2):104-13.

108 Waite R, Vlam RC, Irrera-Newcomb M, Babcock T. The diagnosis less traveled: NPs' role in recognizing adult ADHD. J Am Assoc Nurse Pract. 2013;25(6):302-8.

109 van Emmerik-van Oortmerssen K, van de Glind G, Koeter MW, Allsop S, Auriacombe $\mathrm{M}$, Barta C, et al. Psychiatric comorbidity in treatment-seeking substance use disorder patients with and without attention deficit hyperactivity disorder: results of the IASP study. Addiction. 2014;109(2):262-72.

110 Hamed AM, Kauer AJ, Stevens HE. Why the diagnosis of attention deficit hyperactivity disorder matters. Front Psychiatry. 2015;6: 168.

111 Hinshaw SP, Arnold LE. Attention-deficit hyperactivity disorder, multimodal treatment, and longitudinal outcome: evidence, paradox, and challenge. Wires Cogn Sci. 2015;6(1):39-52.

112 Kiely B, Adesman A. What we do not know about ADHD... yet. Curr Opin Pediatr. 2015;27(3):395-404.

113 Konstenius M, Jayaram-Lindström N, Guterstam J, Beck O, Philips B, Franck J. Methylphenidate for attention deficit hyperactivity disorder and drug relapse in criminal offenders with substance dependence: a 24-week randomized placebo-controlled trial. Addiction. 2014;109(3):440-9.

114 Levin FR, Mariani JJ, Specker S, Mooney M, Mahony A, Brooks DJ, et al. Extended-release mixed amphetamine salts vs placebo for comorbid adult attention-deficit/hyperactivity disorder and cocaine use disorder: a randomized clinical trial. JAMA Psychiatry. 2015;72(6):593-602.

115 Volkow ND, Wang GJ, Fowler JS, Fischman M, Foltin R, Abumrad NN, et al. Methylphenidate and cocaine have a similar in vivo potency to block dopamine transporters in the human brain. Life Sci. 1999;65(1):PL7-12.

116 van Emmerik-van Oortmerssen K, Vedel E, Kramer FJ, Koeter MW, Schoevers RA, van den Brink W. Diagnosing ADHD during active substance use: feasible or flawed? Drug Alcohol Depend. 2017;180:371-5.

117 Conners C. Manual for the Conners' continuous performance test-II. Tonawanda, NY: Multi-Health Systems; 2002

118 Kadesjö B, Janols L, Korkman M, Mickelsson K, Strand G, Trillingsgaard A, et al. The FTF (Five to Fifteen): the development of a parent questionnaire for the assessment of ADHD and comorbid conditions. Eur Child Adolesc Psychiatry. 2004;13(Suppl 3):3-13.

119 American Psychiatric Association. Diagnostic and statistical manual of mental disorders, 4th ed. Washington: American Psychiatric Association; 1994.

120 Rodriguez A, Ginsberg Y, Fernholm A, Nyberg $\mathrm{L}$. [ADHD difficult to diagnose in adults. ASRS v1.1 Self-Report Scales valuable help: now translated to Swedish]. Lakartidningen. 2007;104(18):1398-400.
121 Conners C. The continuous performance test. Toronto: Multi-Health Systems; 1995.

122 Ward MF, Wender PH, Reimherr FW. The Wender Utah Rating Scale: an aid in the retrospective diagnosis of childhood attention deficit hyperactivity disorder. Am J Psychiatry. 1993;150(6):885-90.

123 Conners CK. Conners' rating scales-revised: technical manual. Toronto, Ontario, Canada: Multi-Health Systems; 1997.

124 Barkley R. Attention deficit hyperactivity disorder: a hand-book for diagnosis and treatment. New York: Guildford; 1990.

125 Epstein JN, Kollins SH: Psychometric properties of an adult ADHD diagnostic interview. J Atten Disord. 2006;9(3):50414.

126 Conners CK. Erhardt D, Sparrow E, Staff MHS. The Conners' ADULT ADHD rating scale (CAARS). Toronto: Multi-Health Systems, Inc; 1998.

127 Epstein JN, Johnson D, Conners CK. Conners' adult ADHD diagnostic interview for DSM-IV. North Tonawanda, NY: MultiHealth Systems; 2000.

128 American Psychiatric Association. Diagnostic and statistical manual of mental disorders, 4th edition. Washington: American Psychiatric Association; 2000.

129 Murphy KR, Adler LA. Assessing attentiondeficit/hyperactivity disorder in adults: focus on rating scales. J Clin Psychiatry. 2004; 65(Suppl 3):12-7.

130 Brown TE. Brown attention-deficit disorder scales manual. San Antonio, TX: The Psychological Corporation; 1996.

131 Barratt E. Barratt impulsiveness scale, version 11 (BSI-11). J Clin Psychol. 1995; 51:768-74.

132 Berger I, Goldzweig G. Objective measures of attention-deficit/hyperactivity disorder: a pilot study. Isr Med Assoc J. 2010;12(9):5315.

133 Sheehan DV, Lecrubier Y, Sheehan KH, Amorim P, Janavs J, Weiller E, et al. The Mini-International Neuropsychiatric Interview (M.I.N.I.): the development and validation of a structured diagnostic psychiatric interview for DSM-IV and ICD-10. J Clin Psychiatry. 1998;59(Suppl 20):22-57.

134 Lecrubier Y, Sheehan D, Weiller E, Amorim $\mathrm{P}$, Bonora I, Sheehan $\mathrm{KH}$, et al. The Mini International Neuropsychiatric Interview (MINI). A short diagnostic structured interview: reliability and validity according to the CIDI. Eur Psychiatr. 1997;12(5):224-31.

135 Achenbach TM, Rescorla LA. Manual for the ASEBA school-age forms \& profiles. Burlington, VT: University of Vermont, Research Center for Children, Youth, \& Families; 2001.

136 Brown SA, Myers MG, Lippke L, Tapert SF, Stewart DG, Vik PW. Psychometric evaluation of the Customary Drinking and Drug Use Record (CDDR): a measure of adolescent alcohol and drug involvement. J Stud Alcohol. 1998;59(4):427-38. 